\title{
Changes in Pattern of Adherence to NPIs During the COVID-19 Pandemic
}

\author{
Mobill Clinton $^{1} \cdot$ Janani Sankar ${ }^{1} \cdot$ Venkateswari Ramesh ${ }^{1} \cdot$ Manoj Madhusudan $^{1}$
}

Received: 9 March 2021 / Accepted: 8 April 2021 / Published online: 22 May 2021

(C) Dr. K C Chaudhuri Foundation 2021

To the Editor: During the COVID-19 pandemic, nonpharmaceutical interventions (NPIs) have been the frontline defense against its spread. As we approach a complete unlock, circumstances seemed ideal to have a revision of adherence to NPIs. Usage of NPIs, namely face mask, social distancing, and hand rub among the adults accompanying the children to the OPD in an exclusive pediatric hospital on 15 th February 2021, was assessed. The results were compared with a similar study from October 2020 [1].

Among the 300 participants, an overall decrease in adherence to NPIs was observed. Compliance to social distancing decreased from $86 \%$ to around $45 \%$ and usage of hand rub reduced from $86 \%$ to $24 \%$. But a significant increase in adherence to face mask was observed ( $74 \%$ to $99 \%$ ).

The overall decrease in usage of NPIs could be attributed to "pandemic fatigue" [2]. Another reason could be complacency following flattening of India's COVID-19 curve. The higher usage of masks could be due to better understanding of the disease and strict regulations demanding compulsory wearing of masks in public spaces. But the significant rise in mask usage and relative decrease in adherence to other NPIs could be due to a misconception that face masks are more effective. Similar trend of increase in usage of face mask but a decreased adherence to social distancing and other NPIs was observed by Crane et al. [3]. Analysis of this behavior is needed to understand this trend.

A combination of NPIs has been proven to be more effective in preventing spread of COVID-19 [4], rather than face mask alone. Governments should mandate strategies to reinvigorate public support for NPIs [2]. Despite vaccination, experts recommend continued adherence to NPIs. With the looming question of a second wave outbreak, it is vital that the public remains vigilant and maintains complete adherence to NPIs.

\section{Declarations}

Conflict of Interest None.

\section{References}

1. Clinton M, Sankar J, Ramesh V, et al. Use of proper personal protective measures among parents of children attending outpatient department - an observational study. Indian J Pediatr. 2021. https:// doi.org/10.1007/s12098-020-03624-1.

2. World Health Organization. Regional office for Europe 2020. Pandemic fatigue: reinvigorating the public to prevent COVID-19: policy considerations for member states in the WHO European region. World Health Organization. Regional Office for Europe. Available at: https://apps.who.int/iris/handle/10665/335820. License: CC BY-NC-SA 3.0 IGO. Accessed on 25 Feb 2020.

3. Crane MA, Shermock KM, Omer SB, Romley JA. Change in reported adherence to nonpharmaceutical interventions during the COVID19 pandemic, April-November 2020. JAMA. 2021. https://doi.org/ 10.1001/jama.2021.0286.

4. Bo Y, Guo C, Lin C, et al. Effectiveness of non-pharmaceutical interventions on COVID-19 transmission in 190 countries from 23 January to 13 April 2020. Int J Infect Dis. 2021;102:247-53.

Publisher's Note Springer Nature remains neutral with regard to jurisdictional claims in published maps and institutional affiliations.
Mobill Clinton

mobillclinton@gmail.com

1 Department of Pediatrics, Kanchi Kamakoti CHILDS Trust Hospital, 12A Nageswara Road, Nungambakkam, Chennai, Tamil Nadu 600034, India 